\title{
CUIDADOS PALIATIVOS: O DESAFIO DAS EQUIPES DE SAÚDE
}

\author{
Fernanda de Carvalho Braga* \\ Elizabeth Queiroz \\ Universidade de Brasília - UnB, \\ Brasília, DF, Brasil.
}

Resumo: O avanço tecnológico possibilitou tanto a redução da morte quanto o prolongamento da vida. Essa última traz consigo a necessidade de se pensar em como cuidar de pessoas fora de perspectiva de cura, especialmente porque tal cuidado inclui aspectos psicossociais, com implicações tanto para as relações entre os profissionais quanto com o paciente e sua família. Este estudo teve como objetivo buscar na literatura nacional artigos sobre equipes de saúde que oferecem cuidados paliativos. Realizou-se uma revisão de produção em periódicos nacionais com os descritores cuidados paliativos, equipe de saúde e neonatologia. Foram identificados 62 trabalhos, porém somente 11 atenderam ao critério de relacionar pelo menos dois descritores. Nenhum artigo relacionou as três palavras-chaves. $O$ baixo número de publicações evidencia a necessidade de mais pesquisas nessa área, pois proporcionar qualidade de vida desde o diagnóstico da doença até o momento do óbito representa grande estresse para os profissionais de saúde.

Palavras-chave: Cuidados paliativos. Profissionais de saúde. Trabalho em equipe.

\section{Introdução}

Cuidar de pessoas fora de possibilidade de cura é uma tarefa que requer preparo do profissional de saúde para garantir que o paciente e sua família tenham

* Endereço para correspondência: braga.fernanda.carvalho@gmail.com 
qualidade de vida desde o diagnóstico da doença até o momento do óbito e seus familiares obtenham suporte para o luto. A concepção de cuidado ao paciente fora de perspectiva de cura, como conhecemos hoje, surgiu na década de 1960 com Cicely Saunders, a qual fundou o primeiro hospital voltado para pacientes que estavam fora de possibilidades de cura, o St. Christopher's Hospice, na Inglaterra (Santos, 2011). Desde então, a demanda para cuidar desses pacientes e o número de unidades especializadas para tal fim aumentou, assim como as discussões sobre o tema têm sido cada vez mais frequentes.

Segundo Maciel (2008), a primeira definição de cuidados paliativos publicada pela Organização Mundial de Saúde (OMS) foi em 1990, na qual esses eram vistos como "os cuidados totais e ativos dirigidos a pacientes fora de possibilidade de cura" (p. 16). Tal descrição foi aprimorada e em 2002 passou-se a delegar aos envolvidos com cuidados paliativos a função de, além de aliviar a dor e os desconfortos físicos, dar suporte religioso e psicossocial ao paciente e a seus familiares (World Health Organization [WHO], 2011). O foco passa a ser na qualidade de vida do paciente e de sua família. Além disso, o termo deixa de representar algo que só é oferecido perto da morte, mas que deve ser aplicado desde o diagnóstico da doença (American Academy of Pediatrics [AAP], 2000;WHO, 2011).

Essas considerações devem ser levadas em conta em qualquer momento do desenvolvimento humano, mas a literatura destaca que a sociedade ainda trata a morte de uma criança como um evento anormal, algo incomum (Carter, Hubble, \& Weise, 2006; Ferreira, 2011; Garros, 2003). Não é esperado que crianças sejam diagnosticadas com doenças crônicas ou terminais, que têm como desfecho o falecimento. Porém, esses quadros clínicos acontecem e aparecem desde em fetos até em crianças. Logo, há demanda de cuidados paliativos tanto em Unidades de Terapia Intensiva Pediátrica (UTIP) quanto em Unidades de Terapia Intensiva Neonatal (UTIN).

Os cuidados paliativos envolvem aspectos éticos, psicossociais, religiosos e culturais. Para que todas essas áreas sejam abordadas se faz necessária a formação de uma equipe multiprofissional (AAP, 2000; Bhatia, 2006; Moritz et al., 2008), atuando de forma interdisciplinar. Essa deve estar preparada para aplicar a filosofia paliativa na unidade em que trabalham. Cuidados paliativos em UTIN diferem-se daqueles prestados em outros setores hospitalares. Eles devem ser centrados na família e ter programas para internações de longa duração (Bhatia, 2006). O neonato em cuidados paliativos requer preparo da equipe de saúde para garantir que o paciente e sua família tenham qualidade de vida até o momento do óbito, e acompanhamento do luto para os familiares, conforme definição da OMS (WHO, 2011).

Estudo conduzido por Ferreira (2011) corrobora o conhecimento dos médicos sobre condições necessárias a essa prática. Os relatos des- 
tacam que o cuidar do final da vida deve proporcionar qualidade de vida ao paciente e a seus familiares, ser iniciado desde o diagnóstico, ser aplicado por uma equipe multidisciplinar, entre outras metas de Cuidados Paliativos. Há evidência do estabelecido pelas diretrizes, definições e objetivos sobre Cuidados Paliativos da AAP (2000) e da OMS (WHO, 2011), porém a especificação da aplicação desses cuidados não foi explicitada pelos médicos.

Sabe-se que, no cotidiano do trabalho, os profissionais de saúde esbarram em obstáculos ao aplicar os cuidados paliativos. Segundo a literatura, os profissionais cuidadores encontram dificuldades na tomada de decisão, na comunicação com os familiares, no controle da dor, entre outros (Carter et al., 2006; Costa Filho, Costa, Gutierrez, \& Mesquita, 2008; Hilden et al., 2001). O estudo de Rushton et al. (2006) traz como maior dificuldade o término de um longo relacionamento com o paciente. Além disso, os profissionais também relataram sobre os conflitos com a família do paciente, a morte inesperada e a impossibilidade de aliviar a dor.

Não é novidade que a forma como as pessoas lidam com o morrer modificou-se no decorrer da História. Como a morte faz parte do conceito de cuidados paliativos, é necessário compreender a evolução histórica e visão atual de seu conceito. Morrer faz parte da vida, porém ao longo da História a sociedade parece ter distorcido essa realidade.

Na época anterior à transformação das ciências médicas, a pessoa doente não demorava a ir a óbito. Hoje, com a medicalização das doenças e os avanços tecnológicos para se chegar a um diagnóstico, as pessoas tendem a viver por meses ou até anos após a descoberta de uma doença crônica.

A transferência da morte para o hospital dificulta o acesso ao sujeito que está na iminência de morte. Como consequência, a morte passa a ser ocultada e a aprendizagem do papel de moribundo é restringida. Morrer já não é algo público e coletivo, e sim, privado e individual. Nessa nova configuração, o ambiente hospitalar passa a investir em tecnologia e poder para o combate à morte, em detrimento aos sentimentos e aos questionamentos a ela relacionados (Aguiar, Veloso, Pinheiro, \& Ximenes, 2006; Fernandes, Iglesias, \& Avellar, 2009).

Com o advento da instituição de saúde como local da morte, os profissionais de saúde que nela trabalham tornam-se os responsáveis por lidar com esse acontecimento. Durante a formação acadêmica, o profissional de saúde recebe treinamento focado na vida, sendo a morte percebida como um fracasso (Alencar, Lacerda, \& Centa, 2005; Diniz, 2006; Lima e Souza et al., 2009; Palú, Lambronici, \& Albini, 2004; Tonelli, Mota, \& Oliveira, 2005). Os profissionais não são preparados adequadamente, durante a graduação, para lidarem com a morte de um paciente, esse tema é tratado como um tabu (Bernierr \& Hirdes, 2007). Apesar da tentativa de distanciamento durante o período educacional, a prática profissional faz que 
deparem cotidianamente com a iminência de morte e com a morte. Essa realidade pode gerar, nos profissionais de saúde, sentimentos como alívio, angústia, compaixão, culpa, frustração, medo, impotência, raiva e tristeza (Aguiar et al. 2006, Alencar et al., 2005; Bernierr \& Hirdes, 2005; Carvalho \& Perina, 2003; Costa \& Lima, 2005; Haddad, 2006; Palú et al., 2004).

Sendo assim, é importante conhecer como as equipes de saúde lidam com cuidados paliativos na realidade brasileira. Este trabalho tem como objetivo buscar na literatura nacional estudos sobre equipes de saúde que trabalham cuidados paliativos em neonatologia.

\section{Método}

Foi realizada uma revisão de literatura em periódicos nacionais sobre cuidados paliativos em neonatologia. Os artigos foram pesquisados na base de dados BVS (Biblioteca Virtual em Saúde) que integra: Literatura Latino-Americana e do Caribe em Ciências da Saúde (LILACS); Scientific Electronic Library Online (SCIELO); e Literatura Internacional da área Médica e Biomédica (MEDLINE). Como palavras-chaves utilizou-se cuidados paliativos, equipe de saúde e neonatologia, sendo a primeira combinada com cada uma das demais e as três juntas. A palavra neonatologia foi incluída por tratar-se de estudo preliminar que subsidiou dissertação de mestrado da primeira autora (Braga, 2013). A fim de se conhecer a realidade brasileira sobre o assunto utilizou-se o filtro idioma português. $O$ período pesquisado foi de 2002 a 2012, por abarcar as publicações mais recentes sobre o assunto. Incluiu-se artigos originais e de revisão sobre 0 tema, excluindo-se teses, dissertações, monografias e comunicações.

\section{Resultados}

Encontrou-se 62 publicações: 13 foram excluídas, pois eram repetições de artigos já inclusos na revisão; e nove foram descartadas uma vez que foram divulgadas antes de 2002. Das 40 publicações restantes, resultantes dos descritores cuidados paliativos e equipe de saúde, 16 publicações combinavam os dois temas. Desses 10 eram artigos, três eram teses, duas eram monografias e uma comunicação. Somente uma publicação uniu os temas cuidados paliativos e neonatologia e nenhuma produção foi encontrada relacionando os três descritores. Sendo artigos o foco da presente análise, as teses, as monografias e a comunicação foram excluídas do estudo. 
Das 24 publicações que não entraram para análise, 13 não eram artigos: filmes (um), comunicação (uma), monografias (três), e teses (oito). O restante, apesar de serem artigos e apresentarem as palavras cuidados paliativos e ou equipe de saúde em suas palavras-chaves, seus resumos e ou seus títulos não uniam os temas. Seis artigos trabalham com a perspectiva do paciente e ou sua família sobre cuidados paliativos; três traziam sob diferentes perspectivas a inclusão de um serviço de cuidados paliativos; três focavam em peculiaridades técnicas para a realização dos cuidados paliativos; três discorreram sobre conceitos de cuidados paliativos; e um falava sobre dor crônica.

A maioria dos artigos (04) relaciona morte, cuidados paliativos e profissionais de saúde. Entre os demais: dois relatam características do trabalho em equipe interdisciplinar; um busca apontar o motivo que levou os profissionais de saúde a fazerem parte de uma equipe de cuidados paliativos; um realiza uma revisão bibliográfica sobre ações de enfermeiros perante a realidade de oferecer cuidados paliativos a crianças e adolescentes; um investiga como os profissionais de saúde avaliam a autonomia do paciente em cuidados paliativos; um faz uma revisão bibliográfica sobre a aplicação dos princípios bioéticos no processo de morrer; e um retrata o trabalho com cuidados paliativos de uma equipe de saúde de uma UTIN. O Quadro 1 apresenta os artigos analisados a partir de seus objetivos, metodologia e resultados.

Quadro 1

Artigos analisados

\begin{tabular}{|c|c|c|c|c|c|}
\hline Título & Ano & Autor & Objetivos & Metodologia & Resultados \\
\hline $\begin{array}{l}\text { A passagem } \\
\text { entre a vida e } \\
\text { a morte: uma } \\
\text { perspectiva } \\
\text { psico- } \\
\text { espiritual } \\
\text { em cuidados } \\
\text { paliativos } \\
\text { domiciliares }\end{array}$ & 2003 & $\begin{array}{l}\text { Gimenes, } \\
\text { M.G.G. }\end{array}$ & $\begin{array}{l}\text {-Apoiar a } \\
\text { perspectiva } \\
\text { psico-espi- } \\
\text { ritual para a } \\
\text { compreen- } \\
\text { são da morte } \\
\text { como uma } \\
\text { transição. }\end{array}$ & $\begin{array}{l}\text { - Descrição das } \\
\text { perspectivas } \\
\text { espirituais e } \\
\text { psicológicas } \\
\text { sobre a } \\
\text { morte. } \\
\text { - Definicão } \\
\text { do conceito } \\
\text { psico- } \\
\text { espiritual na } \\
\text { prática dos } \\
\text { cuidados } \\
\text { paliativos }\end{array}$ & $\begin{array}{l}\text {-Sequência } \\
\text { de etapas } \\
\text { psico-espiri- } \\
\text { tuais a serem } \\
\text { seguidas por } \\
\text { pessoas a } \\
\text { fim de res- } \\
\text { ponder às } \\
\text { necessidades } \\
\text { da pessoa } \\
\text { frente à } \\
\text { morte }\end{array}$ \\
\hline
\end{tabular}

(continua) 


\begin{tabular}{|c|c|c|c|c|c|}
\hline $\begin{array}{l}\text { Cuidados } \\
\text { paliativos em } \\
\text { neonatologia: } \\
\text { implemen- } \\
\text { tação de um } \\
\text { programa } \\
\text { multiprofis- } \\
\text { sional }\end{array}$ & 2003 & $\begin{array}{l}\text { Costa, S. } \\
\text { M.M. et } \\
\text { al. }\end{array}$ & $\begin{array}{l}\text {-Relatar a } \\
\text { experiência } \\
\text { do grupo } \\
\text { de cuidados } \\
\text { paliativos } \\
\text { neonatais do } \\
\text { CAISM/ } \\
\text { UNICAMP. }\end{array}$ & $\begin{array}{l}\text { - Relato de } \\
\text { experiência }\end{array}$ & $\begin{array}{l}\text {-Importância } \\
\text { de possuir } \\
\text { uma equipe } \\
\text { capacitada } \\
\text { para atender } \\
\text { as demandas } \\
\text { do Cuidado } \\
\text { Paliativo. }\end{array}$ \\
\hline $\begin{array}{l}\text { A morte no } \\
\text { contexto dos } \\
\text { serviços de } \\
\text { saúde }\end{array}$ & 2004 & $\begin{array}{l}\text { Gomes, } \\
\text { A.P. R., \& } \\
\text { Almeida, } \\
\text { H.O. }\end{array}$ & $\begin{array}{l}\text { - Discutir, } \\
\text { sob o pon- } \\
\text { to de vista } \\
\text { da bioética: } \\
\text { as atitudes } \\
\text { dos profis- } \\
\text { sionais de } \\
\text { saúde dian- } \\
\text { te da apro- } \\
\text { ximação da } \\
\text { morte; im- } \\
\text { plicações } \\
\text { na prática } \\
\text { clínica; } \\
\text { - A impor- } \\
\text { tância da } \\
\text { implan- } \\
\text { tação de } \\
\text { programas } \\
\text { de cuida- } \\
\text { dos paliati- } \\
\text { vos numa } \\
\text { perspectiva } \\
\text { interdisci- } \\
\text { plinar. }\end{array}$ & $\begin{array}{l}\text { • Revisão } \\
\text { crítica e não } \\
\text { sistemática } \\
\text { da literatura } \\
\text { sobre a morte } \\
\text { no contexto } \\
\text { dos serviços de } \\
\text { saúde }\end{array}$ & $\begin{array}{l}\text { •Necessidade } \\
\text { de aborda- } \\
\text { gens que, } \\
\text { possibilitem } \\
\text { a manuten- } \\
\text { ção de uma } \\
\text { sobrevi- } \\
\text { vência que } \\
\text { conserve o } \\
\text { máximo de } \\
\text { qualidade } \\
\text { possível, } \\
\text { preservando } \\
\text { a dignidade } \\
\text { no processo } \\
\text { de morrer. }\end{array}$ \\
\hline $\begin{array}{l}\text { A morte no } \\
\text { cotidiano dos } \\
\text { profissionais } \\
\text { de } \\
\text { enfermagem } \\
\text { de uma } \\
\text { unidade } \\
\text { de terapia } \\
\text { intensiva }\end{array}$ & 2004 & $\begin{array}{l}\text { Palú, L. } \\
\text { A., Labro- } \\
\text { nici, L. M., } \\
\text { \& Albini, } \\
\text { L. }\end{array}$ & $\begin{array}{l}\text { •Compre- } \\
\text { ender a } \\
\text { percepção } \\
\text { de morte dos } \\
\text { profissionais } \\
\text { de enferma- } \\
\text { gem no seu } \\
\text { cotidiano de } \\
\text { trabalho em } \\
\text { uma Unida- } \\
\text { de de Terapia } \\
\text { Intensiva. }\end{array}$ & $\begin{array}{l}\text { - Metodologia } \\
\text { interpretativa; } \\
\text { - Entrevistas; } \\
\text { - Análise em } \\
\text { três momen- } \\
\text { tos: } \\
\text { - a descrição; } \\
\text { - a redução; } \\
\text { - e a compre- } \\
\text { ensão feno- } \\
\text { menológica. }\end{array}$ & $\begin{array}{l}\text {-A morte } \\
\text { geradora de } \\
\text { uma multi- } \\
\text { plicidade de } \\
\text { sentimentos. } \\
\text { •Sentimen- } \\
\text { tos: compai- } \\
\text { xão, culpa, } \\
\text { indiferença, } \\
\text { negação, } \\
\text { envolvimen- } \\
\text { to emocional } \\
\text { e empatia. }\end{array}$ \\
\hline
\end{tabular}

(continua) 


\begin{tabular}{|c|c|c|c|c|c|}
\hline $\begin{array}{l}\text { A formação } \\
\text { na graduação } \\
\text { dos } \\
\text { profissionais } \\
\text { de saúde e } \\
\text { a educação } \\
\text { para o } \\
\text { cuidado de } \\
\text { pacientes fora } \\
\text { de recursos } \\
\text { terapêuticos } \\
\text { de cura. }\end{array}$ & 2009 & $\begin{array}{l}\text { Bifulco, } \\
\text { V.A., \& } \\
\text { lochida, } \\
\text { L. C. }\end{array}$ & $\begin{array}{l}\text { •Desvelar } \\
\text { o tipo de } \\
\text { formação } \\
\text { em nível de } \\
\text { graduação } \\
\text { de profis- } \\
\text { sionais que } \\
\text { integraram a } \\
\text { equipe mul- } \\
\text { tiprofissional } \\
\text { de Cuidados } \\
\text { Paliativos da } \\
\text { Unifesp-EPM } \\
\text { e sua pos- } \\
\text { sível reper- } \\
\text { cussão sobre } \\
\text { sua escolha } \\
\text { profissional. }\end{array}$ & $\begin{array}{l}\text {-Revisão da lite- } \\
\text { ratura nacional } \\
\text { e internacional } \\
\text {-Pesquisa em- } \\
\text { pírica, por meio } \\
\text { da aplicação de } \\
\text { questionário } \\
\text { a uma equipe } \\
\text { multiprofissio- } \\
\text { nal. }\end{array}$ & $\begin{array}{l}\text {-Necessi- } \\
\text { dade de } \\
\text { capacitar os } \\
\text { profissionais } \\
\text { de saúde a } \\
\text { enfrentarem } \\
\text { o cuidado } \\
\text { destes pa- } \\
\text { cientes por } \\
\text { meio de uma } \\
\text { educação } \\
\text { continuada, } \\
\text { fundamen- } \\
\text { tada no co- } \\
\text { nhecimento } \\
\text { do processo } \\
\text { de morte e } \\
\text { morrer. }\end{array}$ \\
\hline $\begin{array}{l}\text { Relações de } \\
\text { trabalho em } \\
\text { equipes inter- } \\
\text { disciplinares: } \\
\text { contribuições } \\
\text { para a consti- } \\
\text { tuição de no- } \\
\text { vas formas de } \\
\text { organização } \\
\text { do trabalho } \\
\text { em saúde. }\end{array}$ & 2009 & $\begin{array}{l}\text { Matos, } \\
\text { E., Pires, } \\
\text { D. E.P., \& } \\
\text { Campos, } \\
\text { G.W.S. }\end{array}$ & $\begin{array}{l}\text {-Pensar as } \\
\text { relações de } \\
\text { trabalho ao } \\
\text { analisar a } \\
\text { contribuição } \\
\text { destas } \\
\text { experiências } \\
\text { para a } \\
\text { constituição } \\
\text { de novas } \\
\text { formas de } \\
\text { organização } \\
\text { do trabalho } \\
\text { em saúde. }\end{array}$ & $\begin{array}{l}\text { •Referencial } \\
\text { teórico: } \\
\text { materialismo } \\
\text { histórico e } \\
\text { dialético; } \\
\text { •Entrevistas } \\
\text { semiestrutura- } \\
\text { das; } \\
\text { •Observação } \\
\text { sistemática. }\end{array}$ & $\begin{array}{l}\text {-A perspec- } \\
\text { tiva inter- } \\
\text { disciplinar } \\
\text { possibilita } \\
\text { melhores re- } \\
\text { lações de tra- } \\
\text { balho entre } \\
\text { profissionais } \\
\text { e entre eles } \\
\text { e doentes/ } \\
\text { família. }\end{array}$ \\
\hline $\begin{array}{l}\text { A } \\
\text { enfermagem } \\
\text { nos cuidados } \\
\text { paliativos } \\
\text { à criança e } \\
\text { adolescente } \\
\text { com câncer: } \\
\text { revisão } \\
\text { integrativa da } \\
\text { literatura. }\end{array}$ & 2010 & $\begin{array}{l}\text { Costa, } \\
\text { T. F., \& } \\
\text { Ceolim, } \\
\text { M.F. }\end{array}$ & $\begin{array}{l}\text { - Identificar } \\
\text { ações de } \\
\text { enfermagem } \\
\text { nos cuidados } \\
\text { paliativos } \\
\text { à criança e } \\
\text { adolescente } \\
\text { com câncer, } \\
\text { consideran- } \\
\text { do as especi- } \\
\text { ficidades da } \\
\text { doença e o } \\
\text { processo de } \\
\text { morte. }\end{array}$ & $\begin{array}{l}\text { •Revisão } \\
\text { bibliográfica: } \\
\text { - Período: } 2004 \\
\text { a 2009; } \\
\text { - Análise: } \\
\text { artigos } \\
\text { - Base de } \\
\text { dados: } \\
\text { Adolec, CINAHL, } \\
\text { LILACS e } \\
\text { PubMed. }\end{array}$ & $\begin{array}{l}\text { •Trabalho } \\
\text { em equipe, } \\
\text { cuidado } \\
\text { domiciliar, } \\
\text { manejo da } \\
\text { dor, diálogo, } \\
\text { apoio à fa- } \\
\text { mília e parti- } \\
\text { cularidades } \\
\text { do câncer } \\
\text { infantil são } \\
\text { fundamen- } \\
\text { tais para a } \\
\text { enfermagem } \\
\text { na assistên- } \\
\text { cia paliativa. }\end{array}$ \\
\hline
\end{tabular}

(continua) 


\begin{tabular}{|c|c|c|c|c|c|}
\hline $\begin{array}{l}\text { Sofrimento } \\
\text { da equipe } \\
\text { de saúde } \\
\text { no contexto } \\
\text { hospitalar: } \\
\text { cuidando } \\
\text { do cuidador } \\
\text { profissional. }\end{array}$ & 2010 & $\begin{array}{l}\text { Kovács, } \\
\text { M.J. }\end{array}$ & $\begin{array}{l}\text {-Abordar } \\
\text { o tema da } \\
\text { morte no } \\
\text { século XXI, } \\
\text { como pro- } \\
\text { fissionais de } \\
\text { saúde a en- } \\
\text { frentam, e as } \\
\text { consequên- } \\
\text { cias na sua } \\
\text { saúde física e } \\
\text { psíquica. }\end{array}$ & $\begin{array}{l}\text { - Relato } \\
\text { teórico; } \\
\text { - Relato de } \\
\text { experiência }\end{array}$ & $\begin{array}{l}\text { •A } \\
\text { intervenção } \\
\text { psicológica } \\
\text { auxilia os } \\
\text { profissionais } \\
\text { a lidarem } \\
\text { com as } \\
\text { questões de } \\
\text { finitude da } \\
\text { vida. }\end{array}$ \\
\hline $\begin{array}{l}\text { Expressões da } \\
\text { subjetividade } \\
\text { no trabalho } \\
\text { de equipes } \\
\text { interdisci- } \\
\text { plinares de } \\
\text { saúde. }\end{array}$ & 2010 & $\begin{array}{l}\text { Matos, } \\
\text { E., Pires, } \\
\text { D. E.P., \& } \\
\text { Ramos, F. } \\
\text { R.S. }\end{array}$ & $\begin{array}{l}\text {-Apreender, } \\
\text { na dinâmica } \\
\text { do trabalho } \\
\text { realizado, os } \\
\text { modos como } \\
\text { os/as traba- } \\
\text { Ihadores/as, } \\
\text { integrantes } \\
\text { dessas equi- } \\
\text { pes, têm } \\
\text { expressado } \\
\text { sua subjetivi- } \\
\text { dade. }\end{array}$ & $\begin{array}{l}\text { •Referencial te- } \\
\text { órico: materia- } \\
\text { lismo histórico } \\
\text { e dialético e da } \\
\text { interdisciplina- } \\
\text { ridade; } \\
\text {-Entrevistas se- } \\
\text { miestruturadas; } \\
\text {-Observação } \\
\text { sistemática. }\end{array}$ & $\begin{array}{l}\text { •Reconheci- } \\
\text { mento em } \\
\text { relação ao } \\
\text { trabalho de- } \\
\text { senvolvido, } \\
\text { interferem } \\
\text { de modo } \\
\text { positivo na } \\
\text { subjetividade } \\
\text { •O cuidar de } \\
\text { pessoas em } \\
\text { situações de } \\
\text { dor e morte } \\
\text { causam } \\
\text { sofrimento } \\
\text { nos } \\
\text { profissionais } \\
\text { de saúde. }\end{array}$ \\
\hline $\begin{array}{l}\text { Autonomia } \\
\text { em cuidados } \\
\text { paliativos: } \\
\text { conceitos e } \\
\text { percepções } \\
\text { de uma } \\
\text { equipe de } \\
\text { saúde. }\end{array}$ & 2010 & $\begin{array}{l}\text { Oliveira, } \\
\text { A.C., \& } \\
\text { Silva, M. } \\
\text { J.P. }\end{array}$ & $\begin{array}{l}\text { - Analisar o } \\
\text { conceito } \\
\text { que a equi- } \\
\text { pe de saú- } \\
\text { de tem da } \\
\text { autonomia } \\
\text { do doente } \\
\text { sem possi- } \\
\text { bilidades } \\
\text { de cura } \\
\text { - identificar } \\
\text { qual é a } \\
\text { atitude } \\
\text { desses pro- } \\
\text { fissionais } \\
\text { diante da } \\
\text { manifesta- } \\
\text { ção dessa } \\
\text { autonomia. }\end{array}$ & $\begin{array}{l}\text { - Estudo } \\
\text { exploratório } \\
\text { descritivo } \\
\text { - Entrevistas } \\
\text { - Análise: } \\
\text { análise de } \\
\text { conteúdo. }\end{array}$ & $\begin{array}{l}\text { - O grupo } \\
\text { I foca o } \\
\text { poder de } \\
\text { decisão do } \\
\text { indivíduo; } \\
\text { - O grupo II } \\
\text { a autono- } \\
\text { mia tem } \\
\text { origem no } \\
\text { indivíduo, } \\
\text { mas é } \\
\text { influencia- } \\
\text { da pelas } \\
\text { relações } \\
\text { sociais e } \\
\text { o modo } \\
\text { de vida da } \\
\text { pessoa. }\end{array}$ \\
\hline
\end{tabular}

(continua) 


\begin{tabular}{|c|c|c|c|c|c|}
\hline $\begin{array}{l}\text { Os princípios } \\
\text { da bioética e } \\
\text { o cuidar da } \\
\text { equipe multi- } \\
\text { disciplinar na } \\
\text { terminalidade } \\
\text { da vida. }\end{array}$ & 2012 & $\begin{array}{l}\text { Santana, } \\
\text { J.C.B., } \\
\text { Dutra, } \\
\text { B.S., } \\
\text { Oliveira, } \\
\text { B. A., } \\
\text { Miranda, } \\
\text { F. R., } \\
\text { Barros, } \\
\text { L. O., \& } \\
\text { Cordeiro, } \\
\text { M.A. }\end{array}$ & $\begin{array}{l}\text { - Levantar na } \\
\text { literatura ma- } \\
\text { teriais que } \\
\text { abordem os } \\
\text { princípios } \\
\text { da bioética e } \\
\text { o cuidar da } \\
\text { equipe mul- } \\
\text { tidisciplinar } \\
\text { na terminali- } \\
\text { dade da vida. }\end{array}$ & $\begin{array}{l}\text { - Revisão } \\
\text { bibliográfica: } \\
\text { - Período: } 2000 \\
\text { a 2010; } \\
\text { - Análise: } \\
\text { artigos } \\
\text { - Base de } \\
\text { dados: } \\
\text { Biblioteca } \\
\text { Virtual de } \\
\text { Saúde (BVS). }\end{array}$ & $\begin{array}{l}\text { - Princípios } \\
\text { de não } \\
\text { maleficên- } \\
\text { cia a bene- } \\
\text { ficência no } \\
\text { cuidar aos } \\
\text { pacientes } \\
\text { terminais } \\
\text { - Autonomia } \\
\text { do pacien- } \\
\text { te no pro- } \\
\text { cesso do } \\
\text { morrer } \\
\text { - Tratamen- } \\
\text { to justo e } \\
\text { igualitário } \\
\text { na termi- } \\
\text { nalidade } \\
\text { da vida }\end{array}$ \\
\hline
\end{tabular}

\section{Discussão}

Os cuidados paliativos associam-se diretamente ao tema da morte e do morrer. Dos artigos inclusos nessa revisão, quatro deles abordam esse tema com o foco voltado para a morte ao invés do processo de morrer. Tal perspectiva desconsidera as diferentes reações de cada um dos envolvidos desde a possibilidade do óbito até o ato do morrer.

Ainda que as reações emocionais estejam intrinsecamente ligadas a essa realidade, pouco se discute sobre as percepções dos profissionais em relação à morte. De acordo com Palú et al. (2004), a convivência com a morte e a iminência do final da vida pode gerar sentimentos como compaixão, culpa, indiferença, negação, envolvimento emocional e empatia em equipes de enfermagem que trabalham em Unidade de Tratamento Intensivo. Tais profissionais têm sua formação voltada para salvar a vida, o que implica sentimentos de fracasso e impotência diante da perda de um paciente. Dessa forma, os autores reforçam a necessidade de estudos sobre a formação desses profissionais para lidar com o final da vida, a fim de prepará-los para enfrentarem tal realidade.

A morte continua como foco nos artigos de Gomes e Almeida (2004) e Kovács (2010). As primeiras discorrem sobre a morte no cotidiano do profissional de saúde, e como o conceito que se tem do final da vida afeta a prática profissional. $O$ cuidado paliativo é inserido na discussão evidenciando-se o aspecto histórico e a participação da equipe multidis- 
ciplinar, a fim de abarcar as demandas. Tal consideração destaca o quanto percepções individuais são estruturantes na definição dos objetivos terapêuticos, representando importante foco a ser trabalhado na formação e educação permanente dos profissionais. No artigo de Kóvacs (2010), cuidados voltados a pacientes fora de possibilidade de cura são apresentados como exemplo de prática que busca modificar a representação da morte, tornando-a um evento natural, consequência da vida. Contudo, a autora destaca que a morte como sinônimo de fracasso profissional ainda é predominante e influencia no trabalho do profissional de saúde.

O estudo de Bifulco e lochida (2009) reforça a importância da formação em nível de graduacão dos profissionais de saúde para lidar com a morte, o morrer e os cuidados paliativos. Os depoimentos de profissionais que trabalham em uma equipe de cuidados paliativos corroboram como o ensino voltado à cura é um obstáculo para a atuação nessa área. A compreensão e aceitação da morte como parte da vida permitem que o profissional visualize a perda de um paciente como consequência de estar vivo e não como fracasso do cuidado. Além disso, as autoras destacam que a percepção da própria finitude pode favorecer o lidar melhor com o fim da vida do outro.

Os quatro artigos supracitados evidenciam a relevância da preparação dos profissionais de saúde para lidar com o processo de morte.Ter contato durante a graduação e em toda a formação com o tema da finitude da vida e dos cuidados paliativos pode ser uma forma de auxiliar aqueles que trabalham cotidianamente com a morte. A importância de aprender a melhor forma de lidar com essa realidade é poder aprimorar os cuidados tanto ao paciente nesse estágio da vida quanto à família. A integração de aspectos técnicos e interpessoais representa uma importante estratégia para o desenvolvimento de competências e habilidades para atuação.

Gimenes (2003) traz a perspectiva espiritual relacionada com a psicológica. Em seu trabalho, a autora primeiramente explicita as perspectivas sobre morte na visão espiritual e na visão psicológica, evidenciando as peculiaridades de cada abordagem. Posteriormente, essas duas correntes são integradas no conceito psicoespiritual voltado para a prática dos cuidados paliativos. A partir de então, sugere-se que as pessoas responsáveis por fornecer os cuidados podem se tornar auxiliares de passagem, aqueles que têm como função auxiliar a pessoa no processo de morrer a passar pelas etapas psicoespirituais que precedem a morte.

O artigo de Gimenes (2003) traz uma forma diferenciada de perceber os momentos que antecedem a morte. A autora apresenta uma nova maneira de abordar tanto a esfera espiritual quanto a psicológica no final da vida. A psicóloga sugere que tal abordagem deve ser utilizada pelos profissionais que estão dispostos a unir a ciência e a espiritualidade. Dessa forma, o estudo busca fornecer aos profissionais de saúde que trabaIham com pessoas fora de possibilidade de cura um guia de como lidar 
com o processo de morrer. Cabe destacar que a espiritualidade tem sido alvo de investigações em diferentes campos do saber por representar um importante apoio para situações em que a possibilidade de perdas encontra-se presente.

O conceito de cuidados paliativos prevê oferecer atenção a aspectos biopsicossociais e espirituais para o paciente e sua família. A equipe multiprofissional caracteriza a possibilidade de abarcar todas essas demandas, desde que atue de forma interdisciplinar. Nessa perspectiva, o trabalho de Matos, Pires e Campos (2009) mostra a relação entre os profissionais de uma equipe de cuidados paliativos, apontando que a dificuldade do grupo estudado baseia-se na relação entre médicos e enfermeiros, enquanto profissionais de referência para tal atuação. Já a qualidade do trabalho apóia-se na disponibilidade da equipe em receber novos integrantes. Os autores destacam que essa forma de intervenção, centrada no paciente e em suas necessidades atendidas por diferentes profissionais, facilita a comunicação entre a equipe e os usuários do sistema no sentido de não prioirzar os conflitos e envolver os familiares e o paciente durante $o$ atendimento. $O$ estudo, apesar de falar de uma equipe de cuidados paliativos, não focaliza a prática dos cuidados paliativos mas as diferenças entre a equipe de cuidados paliativos e a de gerontologia. Pode-se dizer que o foco do artigo foi sinalizar as vantagens e desvantagens de se trabalhar em uma equipe integrada.

Já a pesquisa feita por Matos et al. (2010) enfoca a expressão da subjetividade dos profissionais que trabalham em uma equipe interdisciplinar de cuidados paliativos. Eles dão ênfase na relação de trabalho dos profissionais, explorando a peculiaridade de vivenciar a finitude humana, focada na influência do trabalho em equipe sobre o desempenho dos profissionais de saúde. Para alcançar esse objetivo, após a descrição do trabalho desses profissionais, pontos da filosofia paliativa foram levantados numa tentativa de comparar aspectos teóricos com práticos.

A pesquisa de Costa e Ceolim (2010) buscou na literatura nacional e internacional as ações da equipe de enfermagem oferecidas a crianças e adolescentes fora de possibilidade de cura. Esse artigo mostra as peculiaridades que os profissionais de enfermagem devem lidar diante da iminência de morte de uma criança e ou adolescente, como a comunicação com o paciente e sua família perto do momento da finitude. Os estudos revelam atitudes diferenciadas que devem ser tomadas no contexto do cuidado paliativo, como a formação de uma equipe que trabalhe de forma multidisciplinar a fim de atender todas as demandas dos pacientes e seus familiares. É uma publicação que foca no cuidado paliativo e agrega informações relevantes para os profissionais que trabalham nesse contexto.

Oliveira e Silva (2010) discutem sobre a autonomia do paciente fora de possibilidade de cura, tópico que faz parte da filosofia paliativa. As autoras investigam como os profissionais de saúde tratam dessa questão, 
uma vez que a compreensão teórica do conceito de autonomia influencia na forma como o profissional cuida de seu paciente. Essa questão é de suma importância para aqueles que lidam com pacientes fora de possibilidade de cura, pois envolve os aspectos bioéticos e as decisões de como dar continuidade ao tratamento no final da vida.

A revisão de literatura feita por Santana et al. (2012) discute como os princípios bioéticos da não maleficência, beneficência, justiça e autonomia se enquadram dentro do contexto dos cuidados paliativos. A pesquisa se baseou em 23 materiais sendo 15 artigos e o restante advindos de periódicos relevantes da área de bioética, monografias e livros. Os resultados mostram como os profissionais de saúde devem estar atentos ao cuidado do paciente, para garantir que a prática dos profissionais respeite todos os direitos bioéticos dos pacientes. Dessa forma, os autores ressaltam a necessidade de uma visão multidisciplinar nos cuidados aos pacientes fora de possibilidade de cura.

Finalmente, Costa et al. (2003), descrevem como os cuidados paliativos são fornecidos em uma UTIN. As autoras falam do papel de cada profissional, das reuniões feitas para os profissionais sobre o tema dos cuidados ao paciente fora de possibilidade de cura, e os protocolos criados para atendimento dos neonatos e seus familiares. Na parte final do artigo, as autoras apresentam um caso vivenciado pela equipe. Esse artigo tem como foco os cuidados paliativos e como ele pode ser implantado em uma unidade de tratamento intensivo. As estratégias utilizadas por essa equipe mostram que é possível criar um atendimento ao neonato fora de possibilidade de cura e seus familiares que envolva todos os profissionais da UTIN, trabalhando de maneira interdisciplinar. Esse é o único artigo que fala sobre cuidados paliativos, papel dos profissionais de saúde e neonatologia. Percebe-se que o tema da morte no caso de recém-nascidos é pouco abordado na literatura.

\section{Conclusão}

Dos artigos encontrados, apesar da expressão "cuidados paliativos" aparecer em seus descritores, títulos e ou resumos, poucos se aprofundam na temática paliativista. Foram encontrados artigos que abordam o tema da morte, condição essencial para definição dos cuidados paliativos, deixando a filosofia paliativa em segundo plano, realidade essa também percebida nos textos que falam sobre a relação de trabalho nas equipes interdisciplinares.

Os estudos que dão ênfase aos cuidados paliativos voltam-se para as formas de atuação dos profissionais de saúde junto aos pacientes e aos familiares. São poucos os artigos que buscam conhecer o profissional 
de saúde que vivencia cotidianamente a iminência da morte, algo imprescindível para poder melhorar a qualidade do atendimento.

Os dados analisados sugerem a necessidade de treinamento para que os profissionais sejam capacitados para oferecer tanto o cuidado curativo quanto paliativo, uma vez que as duas preveem atenção integral ao paciente e sua família, portanto compartilham objetivos comuns possíveis de serem dispensados pelos profissionais que compõem a equipe.

Sugere-se, então, futuras pesquisas sobre os desafios que as equipes multiprofissionais de cuidados paliativos enfrentam no seu dia a dia, assim como são necessárias pesquisas sobre o cuidado paliativo em diferentes etapas do desenvolvimento, uma vez que o óbito ainda representa uma vivência bastante estressante para os profissionais de saúde, podendo ser intensificado dependendo das características sociodemográficas dos pacientes.

\title{
Palliative care: The challenge of health teams
}

\begin{abstract}
Technological advances in neonatology enabled the reduction of both death and life extension. The latter brings with it the need to think about how to care for people diagnosed with incurable disease, especially since such care includes psychosocial aspects, with implications for the relationships between professionals and with the patient and his family. This study aimed to look at national literature articles on health teams providing palliative care in neonatology. We conducted a literature review in national journals with descriptors palliative care, health team and neonatology. We identified 62 studies, but only 11 met the criteria relate at least two descriptors. No article listed the three keywords. The low number of publications highlights the need for more research in this area, since to provide quality of life since the disease diagnosis to the time of death is great stress for health professionals.
\end{abstract}

Keywords: Palliative care. Health professionals. Teamwork.

\section{Cuidados paliativos: el reto de los equipos de salud}

Resumen: Los avances tecnológicos en neonatología permitieron tanto la reducción de la muerte como la prolongación de la vida. Este último trae consigo la necesidad de pensar en cómo cuidar a las personas por fuera de una perspectiva de cura, sobre todo porque esa atención incluye aspectos psicosociales, con implicaciones tanto para las relaciones entre los profesionales y con el paciente y su familia. Este estudio tuvo como objetivo examinar artículos de literatura nacionales sobre equipos de salud que se ocupan de cuidados paliativos en neonatología. Se realizó una revisión bibliográfica en revistas nacionales con los descriptores: cuidados paliativos, equipo 
de salud y neonatología. Se identificaron 62 estudios, pero sólo 11 cumplieron con los criterios de relacionar al menos dos descriptores. Ningún artículo relacionó las tres palabras clave. El bajo número de publicaciones destaca la necesidad de realizar más investigaciones en esta área, pues proporcionar calidad de vida a partir del diagnóstico la enfermedad hasta la fecha de la muerte representa un gran estrés para los profesionales de la salud.

Palabras-clave: Cuidados paliativos. Profesionales de la salud. Trabajo en equipo.

\section{Soins palliatifs: le défi des équipes de santés}

Résumé: Les progrès technologiques en néonatologie a permis de réduire à la fois la mort et la prolongation de la vie. Celui-ci apporte avec elle la nécessité de réfléchir à la façon de prendre soin de personnes à l'extérieur d'effectuer une cure, d'autant plus que ces soins comporte des aspects psychosociaux, avec des implications tant pour les relations entre les professionnels et avec le patient et sa famille. Cette étude visait à examiner les articles de la littérature sur les équipes nationales de santé dispensant des soins palliatifs en néonatologie. Nous avons effectué une revue de la littérature dans des revues nationales avec les descripteurs palliatifs équipe soignante et de néonatologie. Nous avons identifié 62 études, mais seulement 11 répondaient aux critères portent sur au moins deux descripteurs. Aucun article énuméré les trois motsclés. Le faible nombre de publications met en évidence la nécessité de poursuivre les recherches dans ce domaine, depuis fournir une qualité de vie à partir du diagnostic de la maladie à la date du décès est un grand stress pour les professionnels de la santé.

Mots-clés: Soins palliatifs. Professionnels de la santé. Travail d'équipe.

\section{Referências}

Aguiar, I. R., Veloso, T. M. C., Pinheiro, A. K. B., \& Ximenes, L. B. (2006). O envolvimento do enfermeiro no processo de morrer de bebês internados em Unidade Neonatal. Acta Paulista de Enfermagem, 19(2), 131-137.

Alencar, S. C. S., Lacerda, M. R., \& Centa, M. L. (2005). Finitude humana e enfermagem: reflexões sobre o (des)cuidado integral e humanizado ao paciente e seus familiares durante o processo de morrer. Família, Saúde e Desenvolvimento, 7(2), 171-180. 
American Academy of Pediatrics, Commitee on Bioethics and Commitee on Hospital Care. (2000). Palliative care for children. Pediatrics, 106(2), 351-357.

Bernierr, J., \& Hirdes, A. (2007). O preparo dos acadêmicos de enfermagem brasileiros para vivenciarem o processo de morte-morrer. Revista Texto \& Contexto Enfermagem, 16(1), 89-96.

Bhatia, J. (2006). Palliative care in the fetus and newborn. Journal of Perinatology, 26, S24-S26.

Bifulco, V. A., \& lochida, L. C. (2009). A formação na graduação dos profissionais de saúde e a educação para o cuidado de pacientes fora de recursos terapêuticos de cura. Revista Brasileira de Educação Médica, 33(1), 92-100.

Braga, F. C. (2013). Cuidados paliativos em unidade de terapia intensiva neonatal: práticas e percepções de profissionais de saúde (Dissertação de Mestrado). Universidade de Brasília.

Carter, B. S., Hubble, C., \& Weise, K. L. (2006). Palliative medicine in neonatal and pediatric intensive care. Child and Adolescente Psychiatric Clinics of North America, 15, 759-777.

Carvalho, M. V. B., \& Perina, E. M. (2003). Cuidados paliativos pediátricos: a "essência do cuidar" da criança/adolescente/familiares nas situações limites. O mundo da Saúde, 27(1), 93-97.

Costa, J. C., \& Lima, R. A. G. (2005). Luto da equipe: revelações dos profissionais de enfermagem sobre o cuidado à criança/adolescente no processo de morte e morrer. Revista Latino-Americana de Enfermagem, 13(2), 151-157.

Costa, S. M. M., Duarte, C. A. M., Salcedo, E. A. C., Perina, E. M., Souza, J. L., Bianchi, M. O., Cardoso, M.S. M. (2003). Cuidados paliativos em neonatologia: implementação de um programa multiprofissional. Mundo Saúde, 27(1), 171-176.

Costa, T. F., \& Ceolim, M. F. (2010). A enfermagem nos cuidados paliativos à criança e adolescente com câncer: revisão integrativa da literatura. Revista Gaúcha de Enfermagem, 31(4), 776-84.

Costa Filho, R. C., Costa, J. L. F., Gutierrez, F. L. B. R., \& Mesquita, A. F. (2008). Como implementar cuidados paliativos de qualidade em Unidade de Terapia Intensiva. Revista Brasileira de Terapia Intensiva, 20(1), 88-92.

Diniz, D. (2006). Quando a morte é um ato de cuidado: obstinação terapêutica em crianças. Cadernos de Saúde Pública, 22(8), 1741-1748. 
Fernandes, P. V., Iglesias, A., \& Avellar, L. Z. (2009). O técnico de enfermagem diante da morte: concepções de morte para os técnicos de enfermagem em oncologia e suas implicações na rotina de trabalho e na vida cotidiana. Psicologia: Teoria e Prática, 11(1), 142-152.

Ferreira, R. A. (2011). Cuidados paliativos em onco-hematologia pediátrica: avaliação psicossocial de cuidadores e percepção de médicos (Dissertação de Mestrado). Universidade de Brasília.

Franco, M. H. P. (2003). Cuidados paliativos e o luto no contexto hospitalar. O Mundo da Saúde (São Paulo), 27(1), 182-184.

Garros, D. (2003). Uma boa morte em UTI pediátrica: é possível isso? Jornal de Pediatria, 79(2), S243-S254.

Gimenes, M. G. G. (2003). A passagem entre a vida e a morte: uma perspectiva psicoespiritual em cuidados paliativos domiciliares. Mundo Saúde, 27(1), 154-158.

Gomes, A. P. R., \& Almeida, H. O. (2004). A morte no contexto dos serviços de saúde. Revista de Saúde do Distrito Federal, 15(1/2), 19-32.

Haddad, D. R. S. (2006). A morte e o processo de morrer de crianças em terapia intensiva pediátrica (Dissertação de Mestrado). Universidade Federal de Minas Gerais, Belo Horizonte, MG.

Hilden, J. M., Emanuel, E. J., Fairdough, D. L., Link, M. P., Foley, K. M., Clarridge, B. C., ... Mayer, R. J. (2001). Attitudes and practices among pediatric oncologists regarding end-of-life care: Results of the 1998 American Society of Clinical Oncology Survey. Journal of Clinical Oncology, 19(1), 205-212.

Kóvacs, M. J. (2010). Sofrimento da equipe de saúde no contexto hospitalar: cuidando do cuidador profissional. O mundo da saúde, 34(4), 420-429.

Lima e Souza, J., Costa, S. M. M., Solcedo, E. A. C., Camy, L. F. S., Carvalho, F. L., Duarte, C. A. M., ... Freston, Y. M. B. (2009). A família, a morte e a equipe: acolhimento no cuidado com a criança. In F. S. Santos (Ed.), Cuidados paliativos: discutindo a vida, a morte e o morrer (pp. 145-164). São Paulo, SP: Atheneu.

Maciel, M. G. S. (2008). Definições e princípios. In R. A. de Oliveira (Eds.), Cuidados paliativos (pp. 15 - 32). São Paulo, SP: Conselho Regional de Medicina do Estado de São Paulo.

Matos, E., Pires, D. E. P., \& Campos, G. W. S. (2009). Relações de trabalho em equipes interdisciplinares: contribuições para a constituição de novas formas de 
organização do trabalho em saúde. REBEn: Revista Brasileira de Enfermagem, 62(6),863-869.

Matos, E., Pires, D. E. P., \& Ramos, F. R. S. (2010). Expressões da subjetividade no trabalho de equipes interdisciplinares de saúde. REME: Revista Mineira de Enfermagem, 14(1), 59-67.

Moritz, R. D., Lago, P. M., Souza, R. P., Silva, N. B., Meneses, F. A., Othero, J. C. B., . . Azeredo, N. (2008). Terminalidade e cuidados paliativos na unidade de terapia intensiva. Revista Brasileira de Terapia Intensiva, 20(4), 422-428. doi: 10.1590/S0103507X2008000400016

Oliveira, A. C., \& Silva, M. J. P. (2010). Autonomia em cuidados paliativos: conceitos e percepções de uma equipe de saúde. Acta Paulista de Enfermagem, 23(2), 212-217.

Palú, L. A., Labronici, L. M., \& Albini, L. (2004). A morte no cotidiano dos profissionais de enfermagem de uma unidade de terapia intensiva. Cogitare Enfermagem, 9(1), 33-41.

Rushton, C. H., Reder, E., Hall, B., Comello, K., Sellers D. E., \& Hutton, N. (2006). Interdisciplinary interventions to improve pediatric palliative care an reduce health care professional suffering. Journal of Palliative Medicine, 9(4), 922-933.

Santana, J. C. B., Dutra, B. S., Oliveira, B. A., Miranda, F. R., Barros, L. O., \& Cordeiro, M. A. (2012). Os princípios da bioética e o cuidar da equipe multidisciplinar na terminalidade da vida. Nursing, 14(167), 209-215.

Santos, F. S. (2011). O desenvolvimento histórico dos cuidados paliativos e a filosofia hospice. In F. S. Santos (Ed.), Cuidados paliativos: diretrizes, humanização e alívio dos sintomas (pp. 3-15). São Paulo, SP: Atheneu.

Tonelli, H. A. F., Mota, J. A. C., \& Oliveira, J. S. (2005). Perfil das condutas médicas que antecedem ao óbito de crianças em um hospital terciário. Jornal de Pediatria, $81(2), 118-125$.

World Health Organization. (2011, 27 de abril). Who definition of palliative care [website]. Recuperado de http://www.who.int/cancer/palliative/en/

Recebido: 07/02/13

Aceito: 02/10/2013 